\title{
The Governance of Genomic Information: Will it Come of Age?
}

\author{
ADÈLE LANGLOIS
}

\begin{abstract}
The completion of the Human Genome Project has opened up unprecedented possibilities in healthcare, but also ethical and social dilemmas in terms of how these can be achieved. Genomic information can be seen as a "global public good" (GPG), in that it is represented by knowledge in the public domain and across national boundaries. Lack of investment, infrastructure and expertise in developing countries means that they are unable to take advantage of these GPG characteristics to address their health needs, fuelling fears of a growing "genomics divide". Some have suggested an international knowledge sharing and capacity building network, a Global Genomics Initiative, as a means to harness the potential of genomics to reduce inequalities in health between North and South. Three UNESCO declarations also call for cooperation between developed and developing countries in genomics research and science and technology in general. Using international relations theories around global governance and networks as a conceptual framework, this paper examines whether these initiatives are likely to succeed in providing effective governance of genomics.
\end{abstract}

\section{Introduction}

Following the completion of the Human Genome Project, the mapping of the entire human genome, genomics is considered by some to have enormous potential to advance medicine and healthcare. Genomic information has been framed as a "global public good" (GPG), because it is available in the public domain and across national boundaries. Lack of investment, infrastructure and expertise in many developing countries means that they are unable to take advantage of these GPG characteristics of genomics to address their health needs, prompting fears of a growing "genomics divide". Two global initiatives, each calling for knowledge sharing and capacity building between North and South in the field of genomics research, may help to bridge this divide. The first of these is a network, the Global Genomics Initiative (GGI), as proposed by academics at the University of Toronto Joint Centre for Bioethics. The second is a series of declarations adopted by UNESCO, the United Nations Educational, Scientific and Cultural Organization. A key reason why the GGI is needed, according to its proponents, is that agreements formed by intergovernmental organisations (of which UNESCO is one) are ineffective. This paper analyses the evolution of these new and traditional forms of governance, using insights from international relations theory. It begins with an overview of thinking around global governance within the discipline of international relations, before discussing the specific case of genomics. It concludes that both the network and UNESCO will have to overcome some of the potential pitfalls facing governance mechanisms identified by international relations theorists if they are to succeed in harnessing the promise of genomics to improve healthcare, particularly in developing countries, while at the same time promoting ethical practice in genomics research. 
What appears to be a complete lack of synergy between the two initiatives may prove a significant barrier to either one achieving these aims.

\section{Global governance}

In 2003, Robert Keohane captured a growing shift in international relations theory when he wrote, "States remain the most powerful actors in world politics, but it is no longer even a reasonable simplification to think of world politics simply as politics

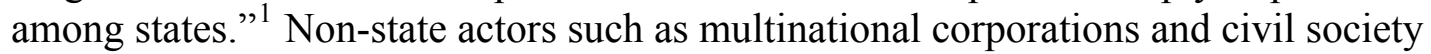
organisations are increasingly becoming players on the world stage. Keohane defines global governance as rule-making and the exercise of power on a global scale, but by entities not necessarily authorised to act by general consensus, with ensuing implications for legitimacy. ${ }^{2}$ James Rosenau uses the same premise, but approaches it from a different angle: because governance systems lack the traditional legitimacy conferred on governments, they can only be effective if the great majority of those they cover agree to them. Under this definition, governance can be said to have an inherent normative purpose; it is derived from shared goals rather than formal authority. ${ }^{3}$ Some theorists question whether governance can as yet be equated with government in terms of efficacy ${ }^{4}$ and view the trend towards more fluidity as neither inevitable nor irreversible. ${ }^{5}$

The concept of governance features in several branches of international relations theory. Regime theory, an antecedent to global governance within the international relations field, looks at the strengths and weaknesses of international bodies and agreements, both formal and informal. As states have often been the main players in these regimes, this theory is particularly pertinent to intergovernmental organisations such as UNESCO. More recently, networks have come to the fore as potential governance mechanisms. Jean-François Rischard and Anne-Marie Slaughter both advocate "networked governance". Their work is of specific relevance to this paper because it is cited by those proposing the Global Genomics Initiative.

\section{Regime theory}

Pierre de Senarclens has commented that governance has taken its place within international relations theory "in the aftermath of the debate about 'regimes'., Whether or not that debate has subsided, regime theory still has much to offer in terms of describing how international bodies or groups work. International regimes reflect collaborative arrangements, formal or informal, within the global system. ${ }^{7}$ These usually coalesce around fairly well-defined issues, such as whale hunting, world trade, ${ }^{8}$ environmental concerns or indeed genomics research. In his edited volume International Regimes (1982), Stephen Krasner defined them as "sets of implicit or explicit principles, norms, rules and decision-making procedures around which actors' expectations converge in a given area of international relations." ${ }^{9}$ Oran Young, in the same book, described regimes somewhat more loosely as "social institutions governing the actions of those interested in specifiable activities (or accepted sets of activities)." ${ }^{\prime 10}$ Within formal regimes, the norms, rules and procedures of Krasner's definition commonly take the form of treaties, conventions or declarations. Where the aim is to reach consensus on legally binding instruments, negotiations tend to be biased towards the interests of the most reluctant states. This lowest common 
denominator effect can be avoided through the adoption of non-binding agreements such as guidelines, voluntary protocols, resolutions or declarations. These have the added advantage of greater flexibility, allowing for adaptation to fluctuating levels of compliance; should some states fulfil their obligations only half-heartedly, or in an unsatisfactory manner, the effort does not have to be completely abandoned. ${ }^{11}$ The corresponding disadvantage lies in the modest enforcement power of such mechanisms. A weak agreement is generally preferable to none at all, however, because state level peer pressure may induce conformity. Methods such as sanctions or unofficial shunning can prove effective in this regard. ${ }^{12}$ Regimes can confer a degree of stability by allowing reciprocal expectations and mutual information networks to develop. The longer parties stay in a relationship, the more interconnected they become and the harder it is to withdraw. "Even though it might formally seem as if treaty regimes have no real power over member states," writes Robert Goodin, "the informal reality is that they typically provide an awful lot of leverage." 13

\section{Intergovernmental organisations}

The most prominent intergovernmental organisations reside within the United Nations (UN) system. Whilst these are important decision-making bodies, they often emerge and subsequently act in a somewhat ad hoc manner, because they do not fall under a global government per se. Overlapping or contradictory functions, mandates, aims and objectives among the different bodies are not uncommon. The World Bank, the United Nations Development Programme, the World Health Organization and UNESCO, for example, will all have some form of policy relating to health and social development, each with different underpinnings. ${ }^{14}$ Lack of coherence can also lead to issues falling between agencies, or uncertainty as to whether action should be taken at global or national levels. ${ }^{15}$ This is particularly the case with non-binding instruments (such as the UNESCO declarations). ${ }^{16}$ With regard to the formulation of policies or agreements within the organisations themselves, David Held has observed that there are often power imbalances between rich and poor states. ${ }^{17}$

\section{Networks}

Some theorists have attempted to move beyond the intergovernmental model. JeanFrançois Rischard has laid out a normative framework for "networked governance" that is designed to circumvent what he perceives to be the cumbersome processes of international institutions. This framework would allow some of the pressing concerns in the world today to be dealt with more effectively, thereby closing a "dangerous governance gap". He has identified twenty issues that he considers both urgent and truly global (as opposed to regional) in nature, including biotechnology and communicable disease ${ }^{18}$ that could be addressed by creating new international public space in the form of single-issue networks, to be known as Global Issue Networks or GINs. ${ }^{19}$ Made up of experts from governments, non-governmental organisations and businesses, with intergovernmental organisations at the helm, these innovative bodies would produce norms and standards and then act as "rating agencies" to assess compliance among both state and non-state actors. ${ }^{20}$ In this regard, then, the GINs would display some of the characteristics of regimes, in compensating for a lack of power to enforce norms by applying a form of peer pressure. Crucially, the timetable for action would be faster than that seen within the more traditional multilateral 
institutions, however. ${ }^{21}$ This is an imperative for Rischard: "Booting-up and delivery times must be fast. Burning global issues cannot wait for the time it takes to negotiate treaties." He predicts that norms and their ensuing reputational effects could be produced more quickly than binding international law, the norms within three to four years of a network being formed. ${ }^{22}$ It should be noted, however, that Rischard's suggestions were first published in 2001; although the GINs may act quickly once established, reaching this stage appears to be a relatively slow process.

Anne-Marie Slaughter, in her recent book A New World Order, also proposes a form of networked governance. Like Rischard's, it would include non-state actors such as international organisations, corporations and non-governmental organisations, but, significantly, with "government networks" as the centrepiece. Her premise is that in the international arena the state is not a unitary actor but a disaggregated one; that is, employees of domestic governmental institutions are increasingly involved in activities that cross national borders, interacting with their counterparts in other countries. These institutions are as likely to be a central bank or utilities body (or perhaps a science and technology watchdog) as they are a foreign office. Where the counterparts are also national government officials, the networks are horizontal; where they are operatives at the supranational level, however, the networks are vertical. Slaughter claims that vertical government networks are relatively rare, because they require that a state delegates its sovereignty to a supranational institution, such as a court or regulatory body. Where this capitulation does happen, however, the supranational institution is enabled to become "maximally effective". Slaughter cites the courts of member states of the European Union and their relations with the European Court of Justice as an example of a vertical government network in practice. $^{23}$

Slaughter goes on to make normative proposals as to how this network model can be taken forward. She envisages a system in which government officials would be explicitly recognised as fulfilling both domestic and international duties. This would mean that they would be answerable to the populace for their actions not just within but also across national borders. Thus the broader policy networks of her version of networked governance (that is, those including non-state actors) would enjoy legitimacy through having accountable government networks at their core. ${ }^{24}$

Slaughter's model of networked governance differs from Rischard's in two fundamental areas. First, the networks she has identified and those she proposes are and will be built around functions rather than single issues. Second, and more significantly, she sees the state, albeit a disaggregated one, as the keystone of legitimacy. Rischard's GINs would act independently, naming and shaming those states unwilling to comply with newly constituted global norms. Given that the GINs would shape norms rather than legislation and would not constitute a form of government, Rischard views the legitimacy question as less cogent than in a context of binding law, but also hopes that the GINs might become a new basis for legitimacy. ${ }^{25}$ By contrast, Slaughter's broader policy networks would depend on government networks to provide their reputational backbone precisely because these would be accountable, not to a nebulous global entity but through an extension of traditional democratic means. 


\section{Genomics governance}

The preceding review of governance theory will provide the tools necessary for an analysis of existing and proposed mechanisms for the governance of genomics. These initiatives stem from the tremendous increase in the profile of genomics in the light of the completion of the sequencing of the human genome. Some have framed genomics as a global public good and believe it has the potential to form part of the solution to current health inequalities, which have themselves spawned an extensive literature in the field of bioethics.

\section{Inequalities of health and GPGs}

Widening disparities in healthcare are deemed the "single gravest problem of medical ethics" by bioethicist Solomon Benatar. ${ }^{26}$ The problem is illustrated by the "10/90 gap", an oft-quoted statistic that has become a kind of shorthand among commentators to describe health inequalities: ninety per cent of the $\$ 56$ billion spent annually on medical research is devoted to mitigating only ten per cent of the global disease burden. ${ }^{27}$ One way to address these inequalities of health may be through the concept of "global public goods" (GPGs); that is, goods that are non-excludable (available to all) and non-rivalrous (consumption by one person does not prevent consumption by another), that can be found in the public domain and whose benefits are available worldwide. These qualities mean that there is no commercial incentive for the production of GPGs. At the national level, governments often find a way to provide public goods, but at the global level the modes of supply are less obvious. ${ }^{28}$ Thus, in a normative sense, effective provision of GPGs is dependent on international cooperation. ${ }^{29}$

Inge Kaul and Michael Faust of the United Nations Development Programme see health as a GPG issue. Since national borders are porous to disease, health conditions are globalised and thus "international cooperation in health has become a matter of self-interest and mutual concern." ${ }^{30}$ One form this cooperation could take would be in the promotion of knowledge, another potentially public good in the sense that its consumption is non-rivalrous. If located in the public domain, knowledge could stimulate research and development into neglected diseases affecting developing countries. The protection of knowledge under intellectual property rights could frustrate such endeavours, however. ${ }^{31}$

\section{Genomics as a GPG}

Like Kaul and Faust, academics at the Canadian Program on Genomics and Global Health at the Joint Centre for Bioethics of the University of Toronto (TJCB) have conceptualised knowledge as a both a public and private good. Peter Singer and Abdallah Daar direct the Program. They are medically trained bioethicists and special advisors to the World Health Organization Genomics Resource Centre, who with colleagues from TJCB formed the Genomics Working Group of the Science and Technology Task Force of the UN Millennium Project. The Program is financed by a diverse range of actors, from Canadian governmental institutions, which provide the bulk of funding, to the World Health Organization to private foundations and universities. TJCB contends that genomics is a GPG in that it is represented by 
knowledge in the public domain and across national boundaries, but is a private good in that its applications may translate into marketable products, protected by international patents. ${ }^{32}$ The idea of genomics as a GPG has been taken up by the Human Genome Organisation, the ethics committee of which stated in 2002 that human genomic databases are GPGs and a public resource and that "knowledge useful to human health belongs to humanity." 33 Similarly, the UNESCO declaration on the human genome deems it the "heritage of humanity" in a symbolic sense and that in its natural form it "shall not give rise to financial gains." 34

\section{Genomics and health}

The TCJB conception of genomics as a GPG links directly with both the inequalities of health literature and the notion of health-related GPGs:

The global public-goods lens magnifies the failures of the global community to realise the full potential of genomics, and shines a light on needed collective actions to harness genomics to improve global health-equity. ${ }^{35}$

Poverty is a direct factor in nearly one third of the global disease load. ${ }^{36}$ It might be expected, then, that access to biotechnological solutions to ill-health would be of second-order importance, after more immediate remedies such as clean water, adequate nutrition and sanitation. ${ }^{37}$ This is not the position of the team at TJCB; with their colleague Richard Smith, they see genomics as crucial to the future of healthcare, with the potential to spawn innovation in the diagnosis, treatment and prevention of some of the major diseases affecting the developing world. ${ }^{38}$ Unless these technologies are harnessed to address such problems, they fear a "genomics divide", whereby inequalities in health between North and South will only broaden. ${ }^{39}$ Theirs is a contested viewpoint. Benatar, who with Daar and Singer has called for global action on inequalities of health, is sceptical of genomics as the way forward. He questions whether biotechnology will really help the poor, if drugs that have already been developed for diseases such as malaria, tuberculosis and HIV/AIDS, as well as several less well-publicised tropical diseases, have not been made available to the very many people in the South that need them. ${ }^{40}$

\section{The Global Genomics Initiative}

TJCB has concluded that collective action will be essential in ensuring that, where the market fails, the GPG characteristics of genomics are harnessed for the benefit of developing countries. ${ }^{41}$ Reflecting the dual public and private nature of genomics, it calls for commitment, of a financial kind from governments and to the sharing of information from the private sector. ${ }^{42}$ According to TJCB, despite the emergence from the Human Genome Project of the principle of universal dissemination, the potential of genomics is not being fulfilled in the South. This is due to practical difficulties, namely lack of investment, infrastructure and expertise. In order to try to address these problems, TJCB proposes a new governance framework for genomics. At first it suggested this framework should take the form of a commission, in an article in the journal Global Governance in 2003: 
An appropriate response by the world community - governments, citizens, and experts from industry and academia - would be to foster global dialogue and provide a forum for shaping the necessary governance framework through a commission on genomics and global health.

By 2004, however, TJCB had moved beyond this initial vision towards a network. ${ }^{44}$ In a report entitled Better Global Governance to Promote Genomics for Development, it put forward a model for a "new global network for governance" as a means to balance the risks and benefits of genomics and guarantee availability of those benefits to developing countries. Using words that would be equally at home in a textbook on global governance to outline the necessity of such an initiative, TJCB wrote, "The governance structure with which we are most familiar - the nation state - is illequipped to effectively tackle global issues."

The initial plans for this network followed Rischard's GIN model, with its membership to include representatives from governments, industry, academia, nongovernmental organisations and civil society. Borrowing directly from Rischard, ${ }^{46}$ TJCB judged treaties insufficient to deal with pressing global predicaments, on the grounds that negotiations are slow and adherence weak, and global commissions unwieldy. The Rischard model was apposite, TJCB argued, because it would be quick to set up, inclusive rather than club-like, responsive, flexible and equitable, encouraging initiation and leadership from the South. ${ }^{47}$ In late 2005 , in an article inviting involvement in and dialogue on the proposed network, TJCB suggested that such a set-up would enable participants to share their needs and aims and create an atmosphere that would allow consensus-building around policy. ${ }^{48}$

Early 2006 saw a further change. This time citing Slaughter as its point of reference (although equating her broader policy networks with Rischard's GINs ${ }^{49}$ ), TJCB stated that although the network should still include actors from international organisations, non-governmental organisations, businesses and other sectors, it should be "underpinned by governments" in order to garner legitimacy and accountability. It accounted for this shift of emphasis as follows:

Building on the work of Slaughter (2004), this model recognises that states are not the only actor, but are important; that states will continue to have distinct interests; that networks can exist alongside more traditional international organisations. ${ }^{50}$

Alongside this new focus on the state, collaboration will also be a key aspect of legitimacy, to be provided through strong leadership and inclusive membership. ${ }^{51}$

The broad objectives of the proposed network, the Global Genomics Initiative (GGI), will be to promote public knowledge, to influence policy on genomics and to provide a forum for dialogue between the public and experts on such policy. A major role will be to put safeguards in place that will allow genomics knowledge to be openly available, but will also minimise the risk of misuse. ${ }^{52}$ TJCB sees the GGI as a potential coordinator of the disparate relevant bodies, from public-private partnerships and bilateral alliances to higher level international organisations: a network of networks. It predicts that the partnerships and alliances, in particular, will benefit from membership of a global network, through expansion, access to knowledge and shared 
resources. Consensus will still be an aim, albeit with the acknowledgement that participants' views will differ. Specific activities may include foresight exercises, promoting knowledge sharing and capacity building in genomics research, designing alternative finance and intellectual property mechanisms and drafting regulatory norms and principles that will harmonise ethical standards for genomic technology research at the global level, incorporating benefit sharing and risk minimisation. ${ }^{53}$

Despite the shift to a more government-centred model, the GGI may yet face problems with regard to legitimacy. Slaughter's model is based on a vision for an explicit accountability pact between government entities and their constituents that goes beyond national borders. This is not present as yet within the international sphere, thus it is not clear that having the backing of states will provide the kudos at global level that TJCB seeks. The GGI, even with its change of emphasis, could still fulfil Keohane's criterion of not being authorised to act by general consensus. Furthermore, the great majority of actors, required by Rosenau for effective governance, who are pre-existing in the field of genomics may not agree to the GGI taking on a coordinating role, particularly with regard to harmonising norms. Although most actors will pronounce themselves in favour of coordination in principle, in practice they may prove less amenable to being coordinated. This is reflected in Slaughter's observation that a maximally effective vertical network has rarity value, because of the unwillingness of states to cede sovereignty.

It is not yet possible to assess whether the GGI will be legitimised through collaboration as its progenitors hope, because clues as to its prospective membership are not readily available, other than in broad sectoral terms. In this context, too, it is appropriate to ask whether general consensus can be achieved. As shown by regime theory, intergovernmental organisations often face difficulties in reaching agreements. It is thus hard to envisage how a wider group of actors, with diverse interests and priorities, will be able to come to an accord that does not lose all potency, particularly within a quicker timeframe than bodies with more circumscribed memberships. At present, it seems, the GGI is still in the planning phase ${ }^{54}$; one of considerable length, given that in 2004 TJCB wrote:

We are now in the process of bringing together some of the best creative minds from these fields [industry, academia, civil society, government] to begin the dialogue and to learn from their experiences so that any decision-making will come from the bottom up.

This protracted set-up period raises questions over whether non-UN-based governance structures can really be initiated more quickly than their intergovernmental counterparts. It might also be the case that allowing bottom-up decision-making could make it doubly hard to fulfil the aim of harmonising norms, should those at the grassroots be working from differing but strongly-held sets of principles.

\section{UNESCO declarations}

Over the last decade UNESCO has produced a series of declarations on genomics, genetics and bioethics: the 1997 Universal Declaration on the Human Genome and Human Rights, the 2003 International Declaration on Human Genetic Data and the 
2005 Universal Declaration on Bioethics and Human Rights. In 1993, the then Director-General of UNESCO, Mr Frederico Mayor, decided that the organisation should set up an International Bioethics Committee, so that it "could play its full role in the world of the future." Approved by the General Conference in November 1993, the first task of the Committee was to prepare an international instrument on the human genome. ${ }^{56}$ UNESCO describes itself as having an "ethical watch mandate" that becomes more and more pertinent as science and technology advances. ${ }^{57}$ The need to keep apace with these changes was the rationale behind both the 2003 and 2005 declarations on, respectively, the specific issue of the handling of human genetic data $^{58}$ and the far broader realm of bioethics. ${ }^{59}$

One of the reasons TJCB gives for why a global genomics initiative is necessary is the ineffectiveness, in its view, of intergovernmental agreements, describing them as "slow to negotiate." been on the drawing board since early $2003,{ }^{61}$ the 2005 declaration took less than two years to finalise once the drafting process had been launched in January $2004^{62}$ and the 1997 declaration took only four years. ${ }^{63}$ Moreover, these lengths of time are comparable to those estimated by Rischard for GINs to complete their norm-setting phase. This perhaps illustrates his point that non-binding norms, which the declarations encapsulate, can be negotiated more quickly than binding legislation such as a convention. Indeed, this was one of the reasons why declaratory rather than conventional formats were chosen. The real key to whether the declarations can be successful as instruments of governance will be in the extent to which they are taken up by states and other actors; having a formalised declaration is just the beginning. This will also be the case with regard to the Global Genomics Initiative; that is, its impact will only be open to measurement once it is established and active.

Like David Held, TJCB has argued that the capacity of developing countries to participate effectively in international negotiations needs to be enhanced. ${ }^{64}$ As shown above, it places a high value on collaboration, particularly with leaders from the South. A review of official documents shows that this took place in the drawing up of all three UNESCO declarations. Notably, the working group or committee for the drafting of each one included a substantial membership from developing countries. ${ }^{65}$ In the negotiating process for the 2005 bioethics declaration, countries from the South were especially active. This is demonstrated by the following three examples. First, in a written consultation with the 190 member states of UNESCO, of the sixty-seven questionnaires returned eleven were from Africa, eight from Asia and the Pacific and six from Latin America and the Caribbean. Second, an extraordinary session of the International Bioethics Committee in Paris in April 2004 was attended by six national bioethics committees from Africa, Latin America and the Caribbean (there were fifteen committees in total). Third, regional consultations with experts were held in Latin America and South-East Asia. ${ }^{66}$

The UNESCO declarations display a strong commitment to capacity building and knowledge sharing in genomics research, similar to that of TJCB. Article 18 of the 1997 declaration reads,

States should make every effort...to continue fostering the international dissemination of scientific knowledge concerning the human genome, human diversity and genetic research and, in that 
regard, to foster scientific and cultural co-operation, particularly between industrialized and developing countries. ${ }^{67}$

The 2005 declaration, on bioethics in general, is also concerned with addressing inequalities in health. To this end, the right to healthcare was included as a general principle from the first outline of a text ${ }^{68}$ and the "10/90 gap" was cited during some of the negotiations. ${ }^{69}$ Article 14 , on social responsibility and health, pertains to social and economic rights as bioethical issues. Citing the promotion of health and social development as "a central purpose of government," it states that progress in science and technology should advance access to healthcare, nutrition, water and improved environmental and living conditions and reductions in marginalisation, illiteracy and poverty. ${ }^{70}$ This concept was introduced by the Latin American group and was initially criticised heavily by some northern states, before being unexpectedly accepted by all countries at the final round of negotiations in June 2005 . $^{71}$

Benatar has questioned whether the aims of UNESCO's 1997 declaration, on the human genome and human rights, will be met. He foresees difficulties in achieving the ideals of freedom of research and protection of human rights and fundamental freedoms that the declaration lays out, referring to its requirement that the human genome should not give rise to financial gain as an example of a principle that may prove hard to implement under private healthcare systems. ${ }^{72}$ Another obstacle, for the 1997 declaration and its progeny, may be their lack of enforcement power. As declarations they are not binding in international law. At the first meeting of the Legal Commission of the International Bioethics Committee in Paris in April 1994, it was discussed whether a convention or a declaration on the human genome would be preferable. It was decided that:

The declaratory instrument should be written in terms sufficiently
general to maintain a certain flexibility in a domain in which science
is continually advancing, and in order to transcend different
cultural, political and religious sensitivities... The convention is the
indispensable complement of the declaration, establishing a more
precisely binding engagement of the responsibility of States,
international organizations, and even of individuals. It has to be
remembered, however, that, in practice, the adoption and
application of a convention could take several years.

The declaratory format was similarly chosen for the bioethics instrument, so that it might receive "the broadest acceptance possible by public authorities, the scientific community and the general public." 74 (Note the appeal to different sectors of society, reminiscent of Rischard, Slaughter and the GGI.) Whilst a non-binding instrument will have been more likely than a binding one to foster broad agreement on what its various principles should be during negotiations, acceptance in terms of implementation will be less certain, precisely because it cannot be enforced. The preamble to the 2003 declaration on human genetic data claims that its predecessor, on the human genome, has received firm support internationally, with member states drawing on it in their legislation, regulations and ethical codes. ${ }^{75}$ As the latter is almost a decade old, this would be expected, now much more so than in 2003. How this support was assessed is unclear, however. The Global Ethics Observatory, a further UNESCO initiative launched in December 2005, will in the future include a 
section giving examples of national and institutional legislation and guidelines, but this is not yet in place. ${ }^{76}$ The section may take some time to compile, because of the need to abstract the relevant information from legal texts and translate it into UNESCO's official languages. ${ }^{77}$

The three declarations vary slightly in what is expected of member states in terms of compliance. Despite the statement in the second declaration about the uptake of the first in legal, regulatory or ethical codes, to be adopted in this manner is not actually an articulated aim of the declaration on the human genome. While several articles allude to national law in the contexts of research ethics, confidentiality and reparation for damage, ${ }^{78}$ the section on promotion of the declaration's principles requires states to do this "through education and relevant means" and "all appropriate measures," whatever they may be, rather than through codification per se. ${ }^{79}$ The International Bioethics Committee is to contribute to the dissemination of the declaration and advise the General Conference on follow up. ${ }^{80}$ These are precisely the types of activities that UNESCO's Bioethics Programme (under which the Committee falls) is engaged in, as well as supporting member states in their endeavours to enhance bioethics education and set up ethics committees, a requirement of the declaration under Article $16{ }^{81}$ The establishment of national bioethics committees is seen as an intermediary step towards the long-term goal of state level legislation on genomics and provides clarity in terms of which national body UNESCO should liaise with in its bioethics activities. According to a member of the Bioethics Programme, it would be unrealistic to expect members to pass legislation upon UNESCO's adoption of a declaration; law-making, at international or national levels, takes time. ${ }^{82}$

By focusing on implementation through education rather than legislative action and delineating its role in this fashion in relation to those of its member states, it may be that UNESCO has been able to avoid some of the confusion and duplication that is sometimes seen in intergovernmental organisations. That this can be achieved with the 2003 and 2005 declarations is less clear. In both of these instruments the legislative push is stronger: states are to "take all appropriate measures, whether of a legislative, administrative or other character," to give effect to the declarations' principles. ${ }^{83}$ This stipulation is reinforced in the 2005 bioethics declaration, one of its stated aims being to provide a universal framework to guide states in formulating legislation, policies or other instruments on bioethics. ${ }^{84}$ The role of UNESCO under the 2003 declaration on human genetic data is ambiguous; it is to take "appropriate action," but what this might entail is not specified. ${ }^{85}$ Thus responsibility for the implementation of the declaration rests on both a member state's government and UNESCO, but the extent to which each actor is responsible relative to the other is blurred. UNESCO's role under the 2005 bioethics declaration is expressed more specifically, in that it is to promote and disseminate the principles contained therein. It is also to "reaffirm its commitment to dealing with bioethics"; again, what this commitment means in practice is not articulated. ${ }^{86}$

\section{Conclusion}

This paper has analysed prospects for the governance of genomics arising from two separate initiatives: the network proposed by TJCB and the UNESCO declarations on genomics, genetics and bioethics. It has been shown that they have analogous aims, 
with regard to capacity building and knowledge sharing in genomics research between North and South and addressing inequalities of health through the advances in medicine that genomics might afford. They also face similar pitfalls, akin to those encountered by many global governance structures before them, a consequence of their both lacking enforcement power. UNESCO has gone some way to mitigating this weakness in its follow up to its Universal Declaration on the Human Genome and Human Rights, by focusing on education and the establishment of national ethics committees, rather than direct adoption by member states of the declaration's principles into their legislative, regulatory or policy frameworks. Although TCJB gives the unwieldiness of intergovernmental organisations and the need for leadership from the South as reasons why a new initiative for the governance of genomics is necessary, UNESCO negotiated the declarations in commensurate or faster lengths of time than that which has passed since plans for the GGI were first elaborated and, on paper at least, involved actors from developing countries in these processes. Thus where the incentive lies for potential members to join the GGI and whether it will succeed in filling the governance gap in genomics research perceived by its proponents are issues that remain open to question.

What is striking in this comparison is the lack of synergy between the two initiatives. TJCB does not mention the UNESCO declarations in any of the publications cited in this paper, nor does the UNESCO website make mention of the proposed GGI. Given the pronounced coherence between the aims of the two bodies, particularly in terms of collaborative action between North and South to enhance genomics capacity, it would be expected that UNESCO would be a prime candidate for membership of the GGI. The involvement of an intergovernmental organisation might go some way towards providing the legitimacy through the state that TJCB seeks for its initiative, although the UNESCO declarations do not fulfil Slaughter's test of maximum effectiveness within a vertical government network, because as non-binding instruments they do not require states to relinquish sovereignty. Furthermore, the GGI could prove a useful partner to UNESCO in its efforts to encourage education around genomics and bioethics, as well as in capacity building and knowledge sharing. If the parallelism between the two initiatives is not addressed, it is possible that the GGI, when it eventually comes to fruition, may agree upon norms and principles for the governance of genomics research that differ from those enshrined in the UNESCO declarations. This could cause confusion or, worse, disillusionment with international norms altogether, among those attempting to conduct scientific research in genomics.

\section{Acknowledgement}

This research is funded by the Wellcome Trust Biomedical Ethics Programme (grant ref. 075315).

\footnotetext{
${ }^{1}$ R. O. Keohane. 2003. Global Governance ad Democratic Accountability. In Taming Globalization: Frontiers of Governance. D. Held and M. Koenig-Archibugi, eds. Cambridge, England. Polity: 130.

${ }^{2}$ Ibid, p. 132.

${ }^{3}$ J. N. Rosenau. 1992. Governance, Order, and Change in World Politics. In Governance Without Government: Order and Change in World Politics. J. N. Rosenau and E-O. Czempiel, eds. Cambridge, England. Cambridge University Press: 4.
} 
${ }^{4}$ H. Yanacopulos. Patterns of Governance: The Rise of Transnational Coalitions of NGOs. Global Society: Journal of Interdisciplinary International Relations July 2005; 19: 252.

${ }^{5}$ D. Held. Democratic Accountability and Political Effectiveness from a Cosmopolitan Perspective. Government and Opposition April 2004; 39: 366.

${ }^{6} \mathrm{P}$. de Senarclens. Governance and the Crisis in the International Mechanisms of Regulation.

International Social Science Journal March 1998; 50: 92.

${ }^{7}$ J. E. Dougherty and R. L. Pfaltzgraff, Jr. 1996. Contending Theories of International Relations: A Comprehensive Survey, $4^{\text {th }}$ edition. United States. Addison-Wesley Educational Publishers Inc: 436.

${ }^{8}$ P. de Senarclens. Regime Theory and the Study of International Organizations. International Social Science Journal 1993; 45: 456.

${ }^{9}$ S. D. Krasner. 1982. Structural Causes and Regime Consequences: Regimes as Intervening Variables. In International Regimes. S. D. Krasner, ed. Ithaca and London. Cornell University Press: 2.

${ }^{10}$ O. R. Young. Regime Dynamics: The Rise and Fall of International Regimes. In International Regimes, ibid, p.93.

${ }^{11}$ O. S. Stokke. 1997. Regimes as Governance Systems. In Global Governance: Drawing Insights from the Environmental Experience. O. R. Young, ed. Cambridge, Massachusetts. MIT Press: 50.

${ }^{12}$ J. A. Caporaso. Towards a Sociology of International Institutions: Comments on the Articles by Smouts, de Senarclens and Jönsson. International Social Science Journal November 2003; 45: 482.

${ }^{13}$ R. E. Goodin. Globalizing Justice. In Taming Globalization, op. cit. note 1, p.82.

${ }^{14}$ Held, op. cit. note 5, pp.368-369.

${ }^{15}$ Ibid, p.371.

${ }^{16}$ Dougherty and Pfaltzgraff, Jr, op. cit. note 7, p.59.

${ }^{17}$ Held, op. cit. note 5, pp.369-370.

${ }^{18}$ J-F. Rischard. High Noon: We Need New Approaches to Global Problem-solving, Fast. Journal of International Economic Law September 2001; 4: 509 and 512-513.

${ }^{19}$ J-F. Rischard. Global Issue Networks: Desperate Times Deserve Innovative Measures. The Washington Quarterly Winter 2002-2003; 26: 24-25.

${ }^{20}$ J-F. Rischard. A Novel Approach to Problem-solving. Global Agenda, January 2003; 1: available as an HTML full text through Academic Search Premier. Rischard, op. cit. note 19, p.25.

${ }^{21}$ Rischard, op. cit. note 19, pp.25-26.

${ }^{22}$ Rischard, op. cit. note 18, pp.517-518, 519 and 521-522.

${ }^{23}$ A-M. Slaughter. 2004. A New World Order. Princeton, New Jersey. Princeton University Press: 1214 and 18.

${ }^{24}$ Ibid, pp.28-29.

${ }^{25}$ Rischard, op. cit. note 18, pp.524 and 522.

${ }^{26}$ S. R. Benatar. Global Disparities in Health and Human Rights: A Critical Commentary. American Journal of Public Health February 1998; 88: 295 and 299.

${ }^{27}$ S. R. Benatar. Commentary: Justice and Medical Research: A Global Perspective. Bioethics 2001; 15(4): 335. P. A. Singer and A. S. Daar. Harnessing Genomics and Biotechnology to Improve Global Health Equity. Science 5 October 2001; 294: 89. See also S. R. Benatar. Reflections and Recommendations on Research Ethics in Developing Countries. Social Science \& Medicine 2002; 54: 1132 and 1138 and G Berlinguer. Bioethics, Health, and Inequality. Lancet 18 September 2004; 364: 1088 .

${ }^{28}$ R. D. Smith. Global Public Goods and Health. Bulletin of the World Health Organization 2003; 81(7): 475.

${ }^{29}$ D. Archibugi and K. Bizzarri. The Global Governance of Communicable Diseases: The Case for Vaccine R\&D. Law \& Policy January 2005; 27(1): 39.

${ }^{30}$ I. Kaul and M. Faust. Global Public Goods and Health: Taking the Agenda Forward. Bulletin of the World Health Organization 2001; 79(9): 869 and 870.

${ }^{31}$ Ibid, p.871.

${ }^{32}$ H. Thorsteinsdóttir et al. Genomics - A Global Public Good? The Lancet 15 March 2003; 361: 892.

${ }^{33}$ HUGO Ethics Committee. Statement on Human Genomic Databases. http://www.hugointernational.org/Statement_on_Human_Genomic_Databases.htm December 2002. (Accessed on 12 July 2006.)

${ }^{34}$ UNESCO. Universal Declaration on the Human Genome and Human Rights. 1997. Paris, France: Articles 1 and 4.

${ }^{35}$ Thorsteinsdóttir et al, op. cit. note 32, p.892. 
${ }^{36}$ Benatar, Reflections and Recommendations on Research Ethics in Developing Countries, op. cit. note 27, p. 1132 .

${ }^{37}$ Ibid.

${ }^{38}$ R. D. Smith et al. Genomics Knowledge and Equity: A Global Public Goods Perspective of the Patent System. Bulletin of the World Health Organization May 2004; 82: 385.

${ }^{39}$ Singer and Daar, op. cit. note 27, pp.87-89.

${ }^{40}$ S. R. Benatar. Human Rights in the Biotechnology Era I. BMC International Health and Human Rights 2002; 2, 3: page numbers not given for citation purposes.

${ }^{41}$ E. Dowdeswell et al. Realising the Promise of Genomics: Exploring Governance. International Journal of Biotechnology 2006; 8(1/2): 133 and 135.

${ }^{42} \mathrm{H}$ Thorsteinsdóttir et al, op. cit. note 32, pp.891-892.

${ }^{43}$ E. Dowdeswell et al. Bridging the Genomics Divide. Global Governance 2003; 9: 1.

${ }^{44}$ Note, however, that many of their stipulations, such as the need for urgency, creative thinking, new financial models and champions from government, industry and civil society remained the same.

Dowdeswell et al, ibid, pp.5-6. T. Acharya et al. Better Global Governance to Promote Genomics for Development. http://www.utoronto.ca/jcb/genomics/documents/CGI-paper.pdf 2004: 6-7.

(Downloaded on 26 April 2005.)

${ }^{45}$ Acharya et al, ibid, pp.1, 2 and 4.

${ }^{46}$ The arguments expressed by Acharya et al can be found in all three of Rischard's papers cited in this paper.

${ }_{47}$ Acharya et al, op. cit. note 44, p.5.

${ }^{48}$ E. Dowdeswell et al. Getting Governance into Genomics. Science and Public Policy December 2005; 32, 6: 497.

${ }^{49}$ Dowdeswell et al, op. cit. note 41, p.137.

${ }^{50}$ Ibid, p.138.

${ }^{51}$ Ibid, p. 140 .

52 Ibid, p. 139 .

${ }^{53}$ Ibid, pp.138-139.

${ }^{54}$ Ibid, p. 140.

${ }^{55}$ Acharya et al, op. cit. note 44, p.6.

${ }^{56}$ Division of the Ethics of Science and Technology of UNESCO. Birth of the Universal Declaration on the Human Genome and Human Rights: 1.

${ }^{57}$ UNESCO. Bioethics. http://www.unesco.org/bioethics (Accessed on 7 October 2004.)

${ }^{58}$ UNESCO. Human Genetic Data: Preliminary Study by the IBC on its Collection, Processing, Storage and Use. 15 May 2002. Paris, France: 2.

${ }^{59}$ UNESCO. Universal Declaration on Bioethics and Human Rights. 2005. Paris, France: Preamble.

${ }^{60}$ Dowdeswell et al, op. cit. note 41, p.137.

${ }^{61}$ Ibid, p. 139.

${ }^{62}$ UNESCO. Presentation given at public meeting. 24 January 2005. Paris, France.

${ }^{63}$ Division of the Ethics of Science and Technology of UNESCO, op. cit. note 56, p.1.

${ }^{64}$ Dowdeswell et al, op. cit. note 43, p.3.

${ }^{65}$ Division of the Ethics of Science and Technology of UNESCO, op. cit. note 56, p.139. UNESCO. Public Hearings Day on Human Genetic Data. 5 May 2003. Paris, France: 2-3. UNESCO. Report of the IBC on the Possibility of Elaborating a Universal Instrument on Bioethics. 13 June 2003. Paris, France: Annex.

${ }^{66}$ Presentation, op. cit. note 62.

${ }^{67}$ UNESCO, op. cit. note 34, Article 18. Article 18 of the International Declaration on Human Genetic Data, UNESCO, is very similar. The only difference is that where the 1997 declaration reads "human genome, human diversity and genetic research," the 2003 declaration reads "human genetic data and human proteomic data." UNESCO. International Declaration on Human Genetic Data. 2003. Paris, France: Article 18. The 2005 Universal Declaration on Bioethics and Human Rights is different again, as follows: "Within the framework of international cooperation, States should promote cultural and scientific cooperation and enter into bilateral and multilateral agreements enabling developing countries to build up their capacity to participate in generating and sharing scientific knowledge, the related know-how and the benefits thereof." UNESCO, op. cit. note 59, Article 24 (2).

${ }^{68}$ UNESCO. Elaboration of the Declaration on Universal Norms on Bioethics: First Outline of a Text. 15 June 2004. Paris, France: 4.

${ }^{69}$ Personal observation. 25 January 2005. UNESCO, Paris, France. 
${ }^{70}$ UNESCO, op. cit. note 59, Article 14.

${ }^{71}$ Interview with a member of the Bioethics Programme, Division of the Ethics of Science and Technology. 29 August 2005. UNESCO, Paris, France.

${ }^{72}$ Benatar, op. cit. note 40, page numbers not given for citation purposes.

${ }^{73}$ Division of the Ethics of Science and Technology of UNESCO, op. cit. note 56, p. 28.

${ }^{74}$ UNESCO. Report of the IBC on the Possibility of Elaborating a Universal Instrument on Bioethics. 13 June 2003. Paris, France: 10.

${ }^{75}$ UNESCO, International Declaration on Human Genetic Data, op. cit. note 67, Preamble.

${ }^{76}$ UNESCO. Global Ethics Observatory. http://www.unesco.org/shs/ethics/geobs, (Accessed on 30 July 2006.)

${ }^{77}$ Interview, op. cit. note 71.

${ }^{78}$ UNESCO, op. cit. note 34, Articles 5, 7 and 8.

${ }^{79}$ Ibid, Articles 20 and 22.

${ }^{80}$ Ibid, Article 24.

${ }^{81}$ Ibid, Article 16. Interview, op. cit. note 71.

${ }^{82}$ Interview, op. cit. note 71 .

${ }^{83}$ UNESCO, International Declaration on Human Genetic Data, op. cit. note 67, Article 23. UNESCO, op. cit. note 59, Article 22.

${ }^{84}$ UNESCO, op. cit. note 59, Article 2.

${ }^{85}$ UNESCO, International Declaration on Human Genetic Data, op. cit. note 67, Article 26.

${ }^{86}$ UNESCO, op. cit. note 59, Article 25. 